\title{
The Effect of ICT Acceptance on Kindergarten Parents' Empowerment: Deliberative Belief as the Mediator
}

\author{
Chun-wen $\operatorname{Lin}^{1}$ \\ ${ }^{1}$ Department of Child Care, National Pingtung University of Science \& Technology, Taiwan \\ Correspondence: Chun-wen Lin, Department of Child Care, National Pingtung University of Science \& \\ Technology, Taiwan. Tel: 886-8-770-3202.
}

Received: July 5, 2018

doi:10.5539/jel.v7n6p37
Accepted: August 2, 2018 Online Published: September 6, 2018

URL: https://doi.org/10.5539/jel.v7n6p37

\begin{abstract}
The primary aim of this study was two-fold: 1) to identify information communication technology (ICT) acceptance of kindergarten parents that influence parents' deliberative belief and empowerment by applying the socio-technical systems theory as theoretical framework; and 2) to examine the mediated effect of deliberative belief between ICT acceptance and empowerment. A total of 949 elementary school and kindergarten parents in Taiwan were asked to complete questionnaire about their ICT acceptance, deliberative belief, and empowerment. Structural equation modeling (SEM) was utilized to evaluate the validity of structural/ latent model. The results revealed that deliberative belief, mediate the relationship between the ICT acceptance and empowerment among parents. ICT acceptance had effect on deliberative belief, and deliberative belief had the effects on empowerment. According to this information, it is recommended that school administrators should encourage parents and teachers together to improve and enhance their deliberative belief, ICT acceptance that may lead to more positive parents' empowerment in school governance.
\end{abstract}

Keywords: ICT acceptance, deliberative beliefs, empowerment, kindergarten parents, structural equation modeling

\section{Introduction}

Information and communication technology (ICT) has become tools of a majority of businesses in order for them to maintain a competitive edge. Because ICT has to be accepted by its intended users to be successful, many ICT acceptance models were proposed for further research. One famous model is "Unified Theory of Acceptance and Use of Technology (UTAUT)" model, synthesized from emerging eight models, based on "Theory of Reasoned Action (TRA)" by Fishbein and Ajzen (1980), "theory of planned behavior, TPB" (Ajzen, 1991). There is also Technology Acceptance Model (TAM), generally considered as the most influential and plays a signified issue in the area of information systems. With the greater innovation and advances of ICT, many school shaved taken the opportunity to apply technology in raising the student academic success, so the rapid changes in ICT products have influenced the development of technology used in the educational field. Students' ICT competencies were the best predictor of their technology use (Charles \& Yidana, 2015).

Over the past decade, research has consistently shown that the degree of parents' empowerment in school is a paramount determinant of children's learning and success. Home was a significant contributing factor for student success, amplifying or diminishing the school effect on learning (Wang et al., 1993), and the parents are likely to connect better with school and teachers when they are empowered. Parents' empowerment can be achieved and increased from basic communication, home improving, volunteering, to advocacy (Shepard \& Rose, 1995). That is, basic communication are the basic skills such as ICT acceptance and deliberative belief and are important contributing factor that are necessary for the improvement of parents' empowerment. Better parent-teacher relation and communication is positively affect students' success at school. Thus, these constitute a very diverse set of contributing factors from socio-technical systems theory, including ICT capacity and acceptance, parents' deliberative belief. Early studies in this area emphasized the characteristics of ICT acceptance. Later, the focus shifted to the qualities of parents' capability of deliberation. In recent decades, researchers have been increasingly analyzing the technology-social interaction. Thus, they not only record the objective indicators of ICT domain, but they also capture social characteristics. 
The overwhelming advances in the Information Technology, especially in the field of digital means of communication, impacted on participation. The application of information and communication technology (ICT) in school governance is one of the important factors that innovates educational administration and parent involvement in schooling is the ultimate goal for education progress. ICT is a newly trend in globalization for education, it had superior capacity to connect teachers and parents within fingertips in few seconds by Line ICT apparatus. The emerging activities enable users to work collaboratively or to monitor social activity by identifying and accumulating relevant information.

The primary purpose of our study was to develop and evaluate a measure of parents' empowerment in school. We developed the Parent empowerment scale drawing from prior research.

Most studies on assessing parents' empowerment in school governance have focused on the parents' ICT acceptance Model with application with planned behavior theory including subject norm, attitude and perceived control. However, this study adopted socio-technical systems theory to investigate how parents' ICT acceptance impacts parents' empowerment in school governance, mediated by deliberative belief using structural equation modeling.

Thus, we proposed

H1. ICT acceptance positively influences deliberative belief.

H2. Deliberative belief positively influences parent empowerment.

H3. Deliberative belief mediates the relationship between ICT acceptance and empowerment among kindergarten parents.

\section{Literature Review}

\subsection{ICT Acceptance}

Many models of the acceptance of technology were proposed and introduced. The latest model is UTAUT which contained 4 factors extracted from eight previous models (Venkatesh, 2000). Simplified UTAUT model had construct as first factor as "Perceived Ease of Use" which means "The degree to which a person believes that using particular system would be free of effort" (Davis, 1989), second factor as "Perceived Usefulness" which was defined as "The degree to which a person believes that using particular system would enhance his job performance" (Davis, 1989), third factor as "Social influence" which means "The person's perception that most people who are important to him think he should or should not perform the behavior in question" (Fishbein \& Ajzen, 1975) and last factor as "Facilitating Condition" which represents "Objective factors in the environment that observers agree make an act easy to accomplish" (Thompson et al., 1991). The other model includes example the theory of reasoned action (TRA) (Fishbein \& Ajzen, 1975), the technology acceptance model (TAM) (Davis, 1989), the motivational model (MM) (Davis, Bagozzi, \& Warshaw, 1989), the theory of planned behavior (TPB) (Ajzen, 1991), the combined TAM and TPB (Taylor \& Todd, 1985), the model of PC utilization (MPTU) (Thomson, Higgin, \& Howell, 1991), the innovation diffusion theory (IDT) (Rogers, 1995) and the social cognitive theory (SCT) (Compeau, Higgin, \& Huff, 1999).

\subsection{The Relationship Between ICT Acceptance and Empowerment}

Parent empowerment in school improves parent's sense of confidence in caring and teaching their children, interacting with teacher and school that their children study and improving academic achievement. Parents' empowerment is related to parents' resilience to demands and their confidence to make decisions and take actions that positively affect their children.

Empowerment involves the extension and transformation of participation in societal democratic process mediated by ICTs (Sabo, Rose, \& Flak, 2008), therefore, ICT acceptance is the basic requirement for citizen to utilizing available technology such as internet to support active empowerment which is reconnecting ordinary citizen with politics and policy-making process (Panopoulou, Tambouris, \& Tarabanis, 2009). Based on the preceding discussion, we proposed the following hypothesis: ICT acceptance is positively related to empowerment.

\subsection{Deliberative Belief}

Borgida, Worth, Lippmann, Damla and Farr (2008) had proposed deliberative belief which contained two dimensions, normative and personal. Deliberative belief is based on deliberative democracy theory which posited to explain how participatory deliberation, democratic discursion in politics leads to empowerment of citizen. In educational institution, the application of "Deliberative Forum" of deliberative project work as a democratic agent of empowerment for students through Empowerment education model (Malka, 2016). Deliberation, on the 
other hand, reflects the inequality between actors which might be fatal for constructive deliberative discourse. Thus, deliberative may have positive effect on empowerment.

Yeh (2017) indicated that ICT-based smart city services increased citizen overall quality of life and the use of ICT can be influenced by social groups. Demetriadis et al. (2003) proposed that introducing ICT into schools could be realized as initiating a "negotiation" process between cultures and the way that technological tools are utilized reflects school "single context" epistemological stance. That is to say, the relation between ICT acceptance and deliberation was building on negotiation process between cultures.

\subsection{Parents Empowerment}

Empowerment is linked to internal resources and a sense of ownership of one's life and means by which people gain control over their life (Mendez, 2010; Zimmerman, 1995). Rappaport (1987) stated that empowerment refers to the processes through which individuals, organizations, or groups gain control over matters that are important to them, and the outcomes of these processes (Rappaport, 1987). The strength of parent to shape meaning to interactions with their children's school is central to the concept of parents' empowerment (Peterson, 2014). That is, parents' empowerment, generally understood as a process, is to acquire a sense of mastery over engagement in school by building their confidence developing coping mechanisms and taking control of the decisions that influence their children's study (Gutirerrez, 1990). Empowerment creates the conditions that allow the individual to participate and make decisions about their own school (Mendez, 2010).

Zimmer refers to outcome of parents' empowerment consisting of three interconnected components. (Zimmerman, 1990, 1995, 2000). First component is intrapersonal, with a feeling of competence, self-efficacy and personal control in parent's approach to matters important to him/her. Second component is interactional, willing to handle matters within environment resolve of parent to change situations and taking control while doing so, and find solution. Third component is behavior aiming at coping and solving problems by participating in school.

\section{Method}

Consistent with the two-step approach advocated by Anderson and Gerbing (1988), we estimated a measurement model before examining the structural model relationship. We utilized AMOS 17.0 to estimate the model.

\subsection{Samples}

Samples from this study were randomly selected from 30 elementary schools and kindergartens in Taiwan. The final sample included 949 parents. There were 262 male (27.6\%) and 687 female (72.4\%). 258 parents' occupation (27\%) were professional, $180(19.0 \%)$ were salesman or for service, 153(16.1\%) were workers, $112(11.8 \%)$ were clerks. Most subjects in the sample were well educated: $5.4 \%$ had junior high degree, $48.5 \%$ had high school degree, $41 \%$ had vocational school degree, 3.8\% had Bachelor's degree.

\subsection{Procedure}

This study was aimed to investigate the relation between ICT acceptance and empowerment for parents in which the role of deliberative belief was mediators. Based on the literature review, previous research, socio-technical systems theory and social exchange theory extended in general incentives rational action model, hypotheses were formulated and examined.

\section{Measure}

Tests of the instrument items' reliability and validity of the measure construct are needed to increase statistical acceptability of the proposed measurement model.

\subsection{ICT Acceptance}

Parents ICT acceptance was measurement by from 3 subscales, "perceived ease-of-use" with 4 items and "perceived usefulness" with 5 items and "intend to use" with 5 items. Parents ICT acceptance scale was measured on a 7-point "strongly disagree" to "strongly agree". The theory of ICT acceptance originated from "Theory of Reasoned Action" and modified with "technology accept model, TAM" by David (1989) in ICT field. Table 1 revealed ICT acceptance scales' structure matrix, reliability, common factors, mean, SD, skewness kurtosis, SMC, CR, AVE. Table 2 showed the ICT acceptance scale credibility. Testing on three factor model resulted in a good fit index $\chi^{2} / \mathrm{df}=2.086<3$, GFI $=0.919, \mathrm{AGFI}=0.877, \mathrm{RMSEA}=0.074<0.08, \mathrm{SRMR}=0.0345<0.05$, $\mathrm{ECVI}=0.806, \mathrm{CFI}=0.984, \mathrm{NFI}=0.961, \mathrm{TLI}(\mathrm{NNFI})=0.979, \mathrm{RFI}=0.950, \mathrm{IFI}=0.984, \mathrm{PNFI}=0.74$. 
Table 1. ICT acceptance scales' structure matrix, reliability, common factors, means, SD, skewness, kurtosis, $\mathrm{SMC}, \mathrm{CR}, \mathrm{AVE}$

\begin{tabular}{|c|c|c|c|c|c|c|c|c|c|}
\hline & usefulness & easy & $\begin{array}{l}\text { Line Intend } \\
\text { to use }\end{array}$ & $\begin{array}{l}\text { Common } \\
\text { factors }\end{array}$ & reliability & SMC & $\begin{array}{l}\text { CR } \\
\text { AVE }\end{array}$ & Mean SD & $\begin{array}{l}\text { Skewness } \\
\text { Kurtosis }\end{array}$ \\
\hline \multirow[t]{2}{*}{ useful1 } & .839 & .484 & .556 & .716 & .91 & .782 & .91 & 5.21 & -.66 \\
\hline & & & & & & & .73 & 1.31 & .43 \\
\hline \multirow[t]{2}{*}{ usefull2 } & .893 & .449 & .480 & .807 & & .787 & & 5.04 & -.61 \\
\hline & & & & & & & & 1.29 & .28 \\
\hline \multirow[t]{2}{*}{ Useful3 } & .911 & .478 & .576 & .844 & & .879 & & 4.97 & -.41 \\
\hline & & & & & & & & 1.33 & -.01 \\
\hline \multirow[t]{2}{*}{ Useful5 } & .836 & .484 & .369 & .714 & & .470 & & 4.65 & -.19 \\
\hline & & & & & & & & 1.39 & -.46 \\
\hline \multirow[t]{2}{*}{ Easy1 } & .169 & .690 & .186 & .570 & .95 & .851 & .94 & 4.97 & -.45 \\
\hline & & & & & & & .81 & 1.39 & -.15 \\
\hline \multirow[t]{2}{*}{ Easy 2} & .688 & .863 & .618 & .801 & & .922 & & 5.05 & -.40 \\
\hline & & & & & & & & 1.43 & -.45 \\
\hline \multirow[t]{2}{*}{ Easy 3} & .680 & .846 & .592 & .777 & & .770 & & 5.01 & -.38 \\
\hline & & & & & & & & 1.43 & -.46 \\
\hline \multirow[t]{2}{*}{ Easy 4} & .657 & .855 & .535 & .770 & & .700 & & 5.00 & -.45 \\
\hline & & & & & & & & 1.37 & -.11 \\
\hline \multirow[t]{2}{*}{ Line 2} & .452 & .441 & .934 & .881 & .95 & .738 & .95 & 5.92 & -1.29 \\
\hline & & & & & & & .82 & 1.36 & -.22 \\
\hline \multirow[t]{2}{*}{ Line 3} & .539 & .459 & .957 & .739 & & .697 & & 5.44 & -.83 \\
\hline & & & & & & & & 1.53 & -.08 \\
\hline \multirow[t]{2}{*}{ Line 4} & .525 & .473 & .941 & .885 & & .933 & & 5.75 & -1.067 \\
\hline & & & & & & & & 1.48 & -.35 \\
\hline \multirow[t]{2}{*}{ Line 5} & .523 & .466 & .943 & .890 & & .914 & & 5.73 & -1.19 \\
\hline & & & & & & & & 1.52 & -.44 \\
\hline
\end{tabular}

Table 2. ICT acceptance scale's Pearson coefficient and AVE

\begin{tabular}{llll}
\hline & usefulness & Easy to use & Intend to use \\
\hline usefulness & $.85(\mathrm{AVE})$ & -- & - \\
Easy to use & $.672^{* *}$ & $.90(\mathrm{AVE})$ & -- \\
Intend to use & $.543^{* *}$ & $.580^{* *}$ & .90 (AVE) \\
\hline
\end{tabular}

Note. ${ }^{* *}$ (Average variance extracted, AVE), ${ }^{* *}=P<0.01$.

\subsection{Deliberative Belief}

Borgida, Worth, Lippmann, Damla and Farr (2008) had proposed deliberative belief scale which was measured on a 7-point "strongly disagree" to "strongly agree". There were two subscale personal deliberative belief and normative deliberative belief. Each subscales had 4 items, the mean and SD, reliability shown as table 3.

Table 3. deliberative belief scale mean and SD, skewness, kurtosis, SMC, composite credibility, AVE, reliability, extracted common factor

\begin{tabular}{llllllllll}
\hline & Mean & SD & skewness & kurtosis & SMC & CR & AVE & reliability & Common factor \\
\hline normative1 & 5.32 & 1.43 & -.72 & -.21 & .79 & .94 & .85 & .89 & .90 \\
normative1 & 5.59 & 1.32 & -.74 & -.25 & .87 & & & & .91 \\
normative1 & 5.48 & 1.34 & -.63 & -.40 & .88 & & & & .86 \\
normatve1 & 5.68 & 1.35 & -.93 & .05 & .85 & & & & .80 \\
\hline personal1 & 5.07 & 1.57 & -.48 & -.71 & .71 & .93 & .78 & .86 & .83 \\
personal1 & 5.11 & 1.38 & -.39 & -.63 & .82 & & & & .91 \\
personal1 & 5.31 & 1.29 & -.65 & .13 & .86 & & & & .91 \\
personal1 & 5.24 & 1.38 & -.63 & -.17 & .72 & & & .87 \\
\hline
\end{tabular}




\subsection{Parent Empowerment Scale}

Parents empowerment scale which is proposed by Ball (2014) was measurement by from 2 subscales, "knowledge" with 4 items and "capability" with 4 items. Parents empowerment scale was measured on a 7-point "strongly disagree" to "strongly agree". Table 4 shows the mean and SD, skewness, kurtosis, SMC, composite credibility, AVE, reliability, extracted common factor of the scale.

Table 4. Parent empowerment scale, mean and SD, skewness, kurtosis, SMC, composite credibility, AVE, reliability, extracted common factor

\begin{tabular}{llllllllll}
\hline & mean & SD & skewness & kurtosis & SMC & CR & AVE & relibaity & Common factor \\
\hline knowledge1 & 4.76 & 1.29 & -.72 & .72 & .62 & .85 & .67 & .90 & .71 \\
knowledge2 & 4.98 & 1.30 & -.64 & .34 & .64 & & & & .73 \\
knowledge3 & 4.86 & 1.32 & -.58 & .41 & .80 & & & & .83 \\
Knoledge 4 & 5.00 & 1.19 & -.42 & .10 & .72 & & & & .80 \\
\hline capability1 & 5.50 & 1.18 & -.87 & .82 & .46 & .72 & .55 & .83 & .56 \\
capability2 & 4.97 & 1.31 & -.65 & .52 & .57 & & & & .65 \\
capability3 & 4.98 & 1.30 & -.71 & .58 & .56 & & & .71 \\
Capability4 & 5.39 & 1.28 & -.77 & .74 & .61 & & & & .75 \\
\hline
\end{tabular}

\section{Results}

After item analysis, item internal consistency and measurement model construct were insured through the analysis of reliability and factor analysis and correlation.

The bivariate correlation analysis had a significant and positive correlation for tested scale items. Table 1, 2, 3 and 4 show the means, descriptive statistics, inter-correlations and internal consistency coefficients of variable used.

\subsection{Analysis Model}

Figure 1 one shows the structure model with the standard coefficients for the research sample. Figure 1 provided support H1, H2, H3. The goodness of fit indics showed $\mathrm{x} 2 / \mathrm{df}=3.89$, GFI=.96, AGFI=.94, NFI=.97, CFI=.98, $\mathrm{NFI}=.97, \mathrm{TLI}=.97, \mathrm{IFI}=.97, \mathrm{RMSEA}=.05, \mathrm{SRMR}=.03, \mathrm{PNFI}=0.76, \mathrm{PCFI}=0.76$.

Finally, this analysis was measured using path analysis to show direct and indirect effects of each construct. The results are reported in Figure 1. After analysis, the direct effect of ICT acceptance on deliberative belief is significant $\mathrm{r}=0.46$. The direct effect of deliberative belief on parent empowerment is significant $\mathrm{r}=0.58$. The direct effect of ICT acceptance on empowerment is significant $\mathrm{r}=0.31$.

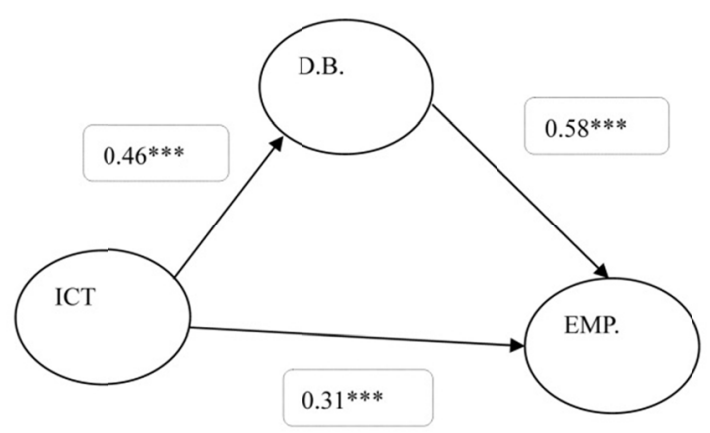

Figure 1. Results of structural equation modeling. Standardized solution for the ICT acceptance-deliberative belief mediation - parent empowerment model

Note. ICT: ICT acceptance; DB: deliberative belief; EMP: empowerment, ${ }^{* * *} p<0.001$. 


\section{Discussion}

\subsection{Discussion}

This study was aimed at investigating the impact of ICT acceptance on empowerment and examining the role of deliberative belief. First, the results indicated that ICT acceptance had a direct impact on empowerment of parents. The results were support by many previous researches. It was important to reveal empirically that the effect of empowerment increased with significant parent IT acceptance.

Secondly the results of SEM indicated that deliberative belief had a positive effect on parent empowerment skill or capacity. That is, with a greater deliberation, there is stronger empowerment in parents. Therefore, deliberative environment could cultivate parent's sense of empowerment. Third, the results of SEM indicated that UCT acceptance had a positive effect on parent empowerment. That is, with a greater ICT acceptance in parents, there is greater empowerment. Therefore, parent ICT acceptance could cultivate empowerment. Despite recognition of meaningful parent engagement as crucially important for achieving student academic outcomes in school involving parent-teacher relationship remains a challenge. It is paramount to advance understanding of how meaningful contributing factor of Parents' empowerment is. Barriers to parent empowerment reduce parents attending parent-teacher association, and also learning outcomes. One method of targeting barriers to access is to capitalize on schools as a technology-social interactive environment for reaching parents who may not otherwise attend PTA. Although some parents may report barriers for Using ICT, such as ICT literacy or acceptance, some parents indicate that participation at school is embarrassing or less deliberative than PTA in other locations. Indeed, schools offer a vehicle for ICT usage, but may also provide deliberative environment to promote parents' empowerment.

\subsection{Limitation}

This research had some limitations that should be addressed. Both predictor and outcome variables rely on self-reported data, which raises the issue of multi-collinearity. Further, our study used a cross-sectional design in order to examine the impact of ICT acceptance over participation mediated by deliberative belief and school climate. Thus, we are unable to make causal inferences. Third, we had adopted deliberative belief variables as mediator, other contextual variables were not include in the study.

\subsection{Directions for Further Research}

There are several suggestions for further research. First, this study examined only the role of deliberative belief. It is possible that there are other variable such as leadership support of government support not included in this study. In the future, the researchers have to consider using social -technical theory which had been claimed blended technology and humanity. It still needs a proof to implementing in school. Because school is getting diverse in many aspects with its various interesting groups and various expectations from parents, parent empowerment is particularly needed within democratic era. We suggest to using quality method based on social and technology dimensions, it will help the researcher to develop the research model with other variables.

\section{Conclusions}

The main purpose of this study was to examine the effects of ICT acceptance and deliberative belief on parent empowerment. To do this, we focused on only the most uncommonly used contributing factor deliberative belief in the literature as mediator. Although this might be considered a limitation of the study, as previously mentioned, our approach allows us to be more focused on the objectives of this study's theoretical framework-social-technical system. This study demonstrates both conceptually and empirically that social factor-deliberative belief and technical factor-ICT acceptance are two different contributing factors that have collaborative working in forming parent empowerment. We show that ICT acceptance and deliberative belief can influence parent empowerment. The findings can shed light on the current literature of kindergarten parent empowerment.

In this study, we aim to expand on the system approach by offering a technology-social model for parents' base on socio-technical system. This research examined the influence of ICT acceptance on empowerment. The finding revealed that deliberative belief as mediators of the relationship between ICT acceptance and empowerment. Thus, this research suggested that more insight is necessary to cultivate parents' deliberative capacity in order to provide empowerment by themselves. Within the greater deliberative system, parents with ICT acceptance, deliberation could elevate their empowerment in schooling and promote school education for children. The finding addresses a stated need in the literature for comprehensive models for evaluating parent empowerment environment within socio-technical system. 
Ackowlegements

The study was funded by a grand from Ministry of Science \& Technology, Taiwan. (MOST-104-2410-H-020-008-).

\section{References}

Ajzen, I. (1991). The theory of planned behavior. Organizational Behavior and Human. Decision Processes, 50, 179-211. https://dx.doi.org/10.1016/0749-5978(91)90020-T

Ajzen, I., \& Fishbein, M. (1980). Understanding attitudes and predicting social behavior. Englewood Cliffs, NJ: Prentice-Hall.

Anderson, J. C., \& Gerbing, D. W. (1982). Some methods for respecifying measurement models to obtain unidimensional construct measurement. Journal of Marketing Research, 19, 453-460. https://dx.doi.org/10.2307/3151719

Charles, B., \& Yidana, I. (2015). Implementation of ICT in learning: A study of students in Ghanaian secondary schools. Procedia-Social and Behavioral Sciences, 194, 1282e1287.

Compeau, D. R., Higgins, C. A., \& Huff, S. (1999). Social cognitive theory and individual reactions to computing technology: A longitudinal study. MIS Quarterly, 23(2), 145-158. https://dx.doi.org/10.2307/249749

Davis, F. D. (1989). Perceived usefulness, perceived ease of use, and user acceptance of information technology. MIS Quarterly, 13(3), 319-340. https://dx.doi.org/10.2307/249008

Davis, F. D., Bagozzi, R. P., \& Warshaw, P. R. (1989). User acceptance of computer technology: A comparison of two theoretical models. Management Science, 35(8), 982-1003. https://dx.doi.org/10.1287/mnsc.35.8.982

Demetriadis, S., Barbas A., Molohides, A., Palaigeorgiou, G., Psillos. D., Vlahavas, I., ... Pombortsis, A. (2003). Cultures in negotiation: teachers' acceptance/resistance attitudes considering the infusion of technology into schools. Computers \& Education, 41(1), 19-37. https://dx.doi.org/10.1016/S0360-1315(03)00012-5

Fishbein, M., \& Azjen, I. (1975). Belief, Attitude, Intention and Behavior. Reading, MA: Addison-Wesley.

Gutierrez, L. (1990). Working with women of color: An empowerment perspective. Social Work Research, 35, 149-153. https://dx.doi.org/10.1287/mnsc.35.8.982

Mendez, J. L. (2010). How can parents get involved in preschool? Barriers and engagement in education by ethnic minority parents of children attending Head Start. Cultural Diversity \& Ethnic Minority Psychology, 16, 26-36. https://dx.doi.org/10.1037/a0016258

Panopoulou, E., Tambouris, E., \& Tarabanis, K. (2009). e-Participation initiatives: How is Europe progressing?. European Journal of e-Practice, 7, 15-26. https://dx.doi.org/10.1287/mnsc.35.8.982

Peterson, N. A. (2014). Empowerment theory: clarifying the nature of higher-order multidimensional constructs. American Journal of Community Psychology, 53, 96-108. https://dx.doi.org /10.1007/s10464-013-9624-0

Rappaport, J. (1987). Terms of empowerment exemplars of prevention: toward a theory for community psychology. American Journal of Community Psychology, 15, 121-148. https://dx.doi.org /10.1007/bf00919275

Rogers, E. M. (1983). Diffusion of Innovations (3rd ed.). New York: The Free Press.

Sabo, O., Rose, J., \& Flak, L. S. (2008). The shape of e-participation: Characterizing an emerging research area. Government Information Quarterly, 25(3), 400-428.

Shepard, R., \& Rose, H. (1995). The power of parents: An empowerment model for increasing parental involvement. Education, 115 (3), 373-376.

Taylor, S., \& Todd, P. A. (1985). Understanding information technology usage: A test of competing models. Information Systems Research, 6(2), 144-176. https://dx.doi.org/10.1287/isre.6.2.144

Thompson, R. L., Higgins, C. A., \& Howell, D. M. (1991). Personal computing: toward a conceptual model of utilization. MIS Quarterly, 15(1), 124-143. https://dx.doi.org/10.2307/249443

Venkatesh, V. (2000). Determinants of perceived ease of use: integrating control, intrinsic motivation, and emotion into the technology acceptance model. Information Systems Research, 11, 342-365. https://dx.doi.org/10.1287/isre.11.4.342.11872 
Wang, M. C., Haertel, G. D., Walberg, H. J. (1993). Toward a knowledge base for school learning. Review of Educational Research, 63, 249-294. https://dx.doi.org/10.3102/00346543063003249

Yeh, H. P. (2017). The effects of successful ICT-based smart city services: From citizens' perspectives. Government Information Quarterly, 34(3), 556-565. http://dx.doi.org/10.1016/j.giq.2017.05.001

Zimmerman, M. A. (1990). Taking aim on empowerment research: On the distinction between individual and psychological conceptions. American Journal of Community Psychology, 18, 169-177. https://dx.doi.org/10.1007/bf00922695.

Zimmerman, M. A. (1995). Psychological empowerment: issues and illustrations. American Journal of Community Psychology, 23, 581-599. https://dx.doi.org/10.1007/bf02506983.

Zimmerman, M. A. (2000). Empowerment theory: psychological, organizational, and community levels of analysis. In J. Rappaport \& E. Seidman (Eds.), Handbook of community psychology. New York: Kluwer academic/Plenum Publishers.

\section{Copyrights}

Copyright for this article is retained by the author, with first publication rights granted to the journal.

This is an open-access article distributed under the terms and conditions of the Creative Commons Attribution license (http://creativecommons.org/licenses/by/4.0/). 